\title{
PSA Level Greater than One
}

National Cancer Institute

\section{Source}

National Cancer Institute. PSA Level Greater than One. NCI Thesaurus. Code C138949.

A blood concentration of prostate specific antigen greater than $1 \mathrm{ng} / \mathrm{mL}$. 